\title{
ESTUDO QUALI-QUANTITATIVO E PERCEPÇÃO AMBIENTAL DA ARBORIZAÇÃO DO SETOR JARDIM SEVILHA, GURUPI - TO
}

\author{
QUALI-QUANTITATIVE RESEARCH AND ENVIRONMENTAL PERCEPTION OF THE \\ JARDIM SEVILHA DISTRICT'S AFFORESTATION, GURUPI - TO
}

\author{
Romualdo Júlio Cavalcante Wanderley¹, Claudia Alicia Marín Perez², Dário Rabêlo", \\ Patrícia Aparecida de Souza ${ }^{3}$, Marcos Giongo ${ }^{4}$, André Ferreira dos Santos ${ }^{4}$
}

\section{RESUMO}

A importância da arborização urbana como elemento natural componente do ecossistema urbano reside nas funções e benefícios que ela desempenha. Para se conhecer a arborização urbana, é necessária a sua avaliação, o que depende da realização de inventário. Dessa forma, o objetivo deste trabalho foi avaliar a arborização e a percepção ambiental dos moradores do setor Jardim Sevilha da cidade de Gurupi - TO. A arborização das vias públicas do Jardim Sevilha apresentou-se constituída de 212 indivíduos arbustivoarbóreos e palmeiras, pertencentes a 19 famílias, 35 gêneros e 38 espécies. No estudo, $26,32 \%$ das espécies eram nativas do Bioma Cerrado, enquanto que $73,68 \%$ eram exóticas. Todavia, em relação ao total de indivíduos, $91,98 \%$ eram exóticos e somente $8,02 \%$ eram nativos do bioma. A espécie de maior ocorrência foi Licania tomentosa, com $54,25 \%$ do total de indivíduos. A maioria dos indivíduos apresentouse em boas condições fitossanitárias e sem necessidade de poda. Diante dos resultados sobre percepção ambiental, pode se dizer que a maioria dos entrevistados tem conhecimento sobre a importância da arborização em vias públicas. Entre os benefícios mais observados estão o fornecimento de sombra e a amenização da temperatura.

Palavras-chave: Inventário; Desenvolvimento sustentável; Diversidade biológica.

\section{ABSTRACT}

The relevance of urban afforestation as a natural element of the urban ecosystem lies in the features and benefits that it performs. In order to know about the urban afforestation, it is necessary to evaluate it, which depends on the conduction of an inventory. Thus, the objective of this research was to evaluate the afforestation and the residents' environmental perception in Jardim Sevilha district in Gurupi - TO. The afforestation of the public roads in Jardim Sevilha was constituted of 212 shrub-tree specimens and palm trees, belonging to 19 families, 35 genera and 38 species. Within the study, $26.32 \%$ of species were native of Cerrado, while $73.68 \%$ were exotic. Nonetheless, in relation to all specimens, $91.98 \%$ were exotic and only $8.02 \%$ were native to the biome. The most frequent species was Licania tomentosa, with $54.25 \%$ of specimens. Most specimens appeared to be in good phytosanitary conditions and without pruning needs. According to the results related to environmental perception, it can be said that most interviewees are aware of the importance of afforestation on public roads. The provision of shade and the mitigation of temperature are among the most observed benefits.

Keywords: Inventory; Sustainable development; Biodiversity.

Recebido em 08.07.2017 e aceito em 15.01.2018

1 Engenheiro Florestal. Graduado. Universidade Federal do Tocantins. Gurupi - TO. Email: julio_cavalcanti@hotmail.com, dario.rabelo@yahoo.com.br

2 Bióloga. Mestre. Universidade Federal do Tocantins. Gurupi - TO. Email: biologia.claudiamarin@gmail.com

3 Engenheira Florestal. Drạ. Prof ${ }^{a}$. Adjunta da Universidade Federal de São João Del-Rei. São João del-Rei - MG. Email: patriciaapsouza@uft.edu.br

4 Engenheiro Florestal. Dr. Prof. Adjunto da Universidade Federal do Tocantins. Gurupi - TO. Email: giongo@uft.edu.br, andrefs@uft.edu.br 


\section{INTRODUÇÃO}

A Arborização Urbana, também chamada de Florestas Urbanas, inclui os diversos espaços no tecido urbano passíveis de serem trabalhados com o elemento árvore, tais como: arborização de ruas, praça, parque, jardim, canteiro central de ruas e avenidas e margens de corpos d'água (GOMES, 2012).

Bobrowski, Biondi e Figueiredo Filho (2012) ressaltaram a importância das funções e benefícios que a arborização urbana desempenha, como elemento natural componente do ecossistema urbano. Segundo os autores, por meio de um correto planejamento e eficaz implantação da arborização procura-se reduzir o grau de artificialidade das cidades e interferir positivamente na qualidade de vida da população urbana.

A arborização das cidades, de acordo com a Cemig (2011), além da estratégia de amenização de aspectos ambientais adversos, é importante sob os aspectos ecológico, histórico, cultural, social, estético e paisagístico, contribuindo para: a manutenção da estabilidade microclimática; o conforto térmico associado à umidade do ar e à sombra; a redução da poluição; a melhoria da infiltração da água no solo; a proteção e direcionamento do vento; a proteção dos corpos d'água e do solo; a conservação genética da flora nativa; o abrigo à fauna silvestre; entre outras funções.

Do ponto de vista estético, a arborização contribui através das qualidades plásticas (cor, forma, textura) de cada parte visível de seus componentes; a vegetação guarnece e emoldura ruas e avenidas, contribui para reduzir o efeito agressivo das construções que dominam a paisagem urbana, devido à sua capacidade de integrar os vários componentes do sistema. $\mathrm{E}$ quanto ao aspecto psicológico, contribui com relação à satisfação que o homem sente ao contato com a vegetação e com o ambiente criado (GOMES, 2012).

O inventário da arborização tem como objetivo geral conhecer o patrimônio arbustivo e arbóreo de uma localidade. Tal levantamento é fundamental para o planejamento e manejo da arborização, fornecendo informações sobre a necessidade de poda, tratamentos fitossanitários ou remoção e plantios, bem como para definir prioridades de intervenções (MELO; LIRA FILHO; RODOLFO JUNIOR, 2007). Nesse contexto, a realização do inventário da arborização de vias públicas permite demarcar com clareza a população total de árvores de ruas e a composição atual da arborização.

Há de se considerar, do mesmo modo, o levantamento da percepção dos moradores para que o planejamento e manejo da arborização atendam às necessidades social, ambiental, paisagística e de sustentabilidade. Nesse sentido, Roppa et al. (2007) definem percepção ambiental como sendo o ato em que os seres humanos são capazes de perceber o ambiente em que eles estão inseridos e assim possam aprender a protegê-lo. 
Segundo Viezzer et al. (2016), os principais benefícios citados por estudos de percepção da arborização urbana são: sombra, conforto térmico, diminuição da temperatura, atenuação da poluição, beleza cênica e bem-estar. Esses mesmos autores relatam que, em diversas cidades brasileiras, a população reconhece o papel da arborização urbana, principalmente em relação à sua influência no microclima.

Já Brun, Longhi e Brun (2009) destacaram, em seus estudos, que os moradores apresentam uma percepção de que a árvore é mais um elemento do mobiliário urbano, com funções de abrigo (do calor), do que um elemento natural, fundamental na manutenção da sustentabilidade da cidade e da aproximação do homem com o meio natural.

Assim, existe a necessidade de um programa de educação ambiental junto à comunidade sobre a importância da arborização urbana para a melhoria da qualidade de vida e higidez ambiental nos centros urbanos (BRUN; LONGHI; BRUN, 2009).

Dessa forma, o objetivo deste trabalho foi avaliar a arborização e a percepção ambiental dos moradores do setor Jardim Sevilha da cidade de Gurupi - TO, a fim de verificar os aspectos da arborização, pertinentes à metodologia, e sua relação com a população local.

\section{MATERIAL E MÉTODOS}

O estudo foi realizado no município de Gurupi - TO, no setor Jardim Sevilha. Gurupi

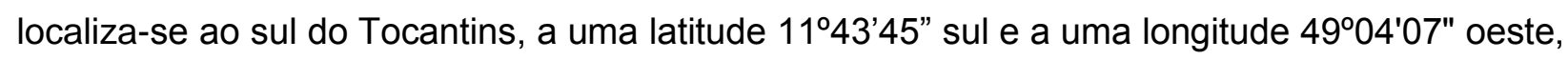
estando a uma altitude de 287 metros. O município de Gurupi se encontra a 245 km de Palmas, capital do Estado, e a 742 km de Brasília, capital federal (SMI, 2013). O clima da região é do tipo C2wA'a" úmido subúmido com moderada deficiência hídrica, conforme a classificação de Thornthwaite (SEPLAN, 2013). No município se encontram duas regiões fitoecológicas, as quais são a Floresta Estacional e o Cerrado (Bioma Cerrado).

Gurupi é a terceira maior cidade do Tocantins, sendo o polo regional de toda a região sul do estado. Suas avenidas têm os nomes dos estados brasileiros, sendo a principal a Avenida Goiás; enquanto as ruas, apesar de renomeadas para homenagear personalidades históricas, ainda são chamadas de acordo com sua numeração.

Jardim Sevilha se encontra em expansão populacional, devido à presença do Instituto Federal de Educação, Ciência e Tecnologia do Tocantins (IFTO) e da proximidade ao campus da Universidade Federal do Tocantins (UFT). Esse crescimento vem causando desequilíbrio na estrutura da arborização local, e consequentemente na fauna associada. Por isso, há a necessidade de um estudo ambiental da área, especificamente da arborização e da percepção ambiental dos moradores. 
O setor Jardim Sevilha faz divisa com o campus universitário da UFT; possui treze ruas, entre estas, uma alameda; e caracteriza-se em sua maioria como residencial (Figura 1).

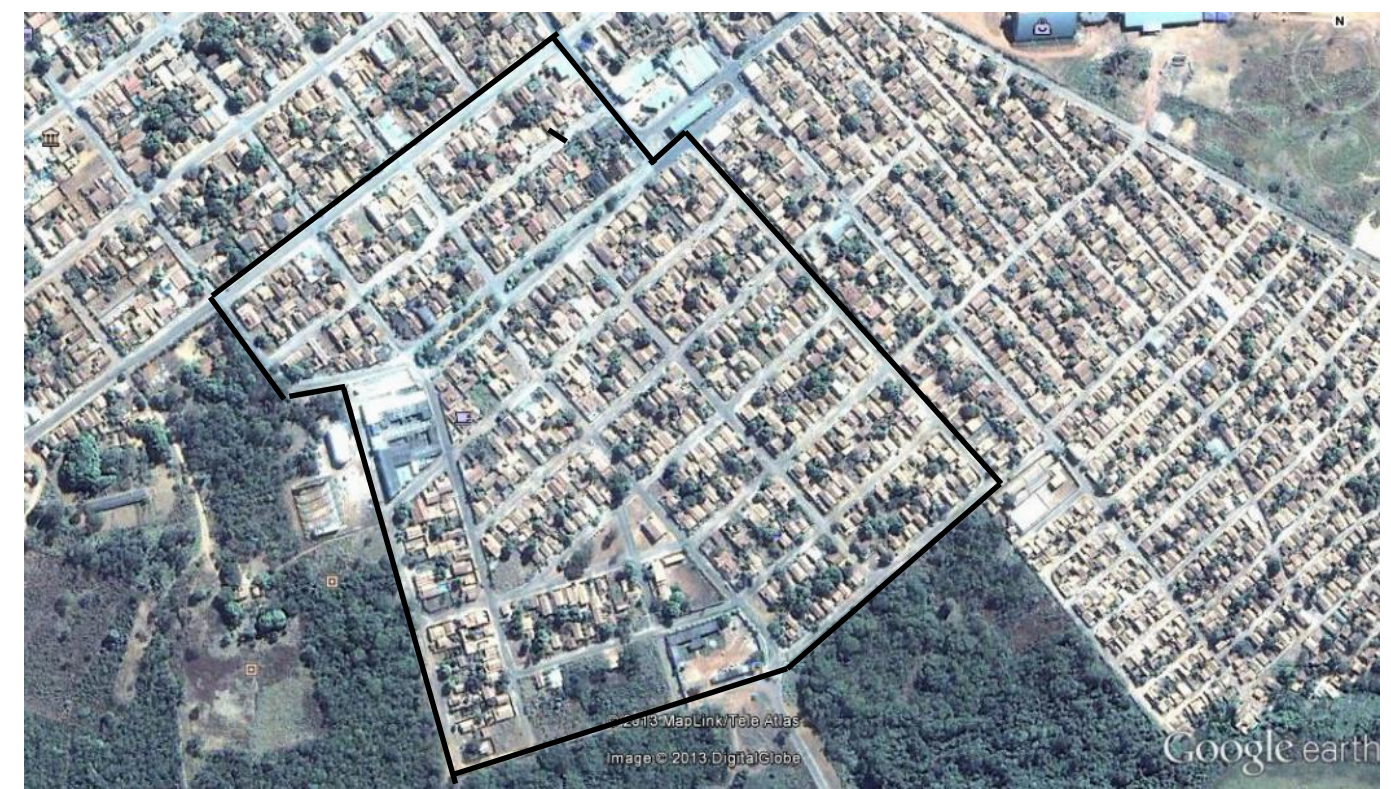

Figura 1. Área de estudo demarcada, Jardim Sevilha, Gurupi - TO Fonte: Google Earth (2013) Figure 1. Delimited study area, Jardim Sevilha, Gurupi - TO

O levantamento da arborização constou da identificação botânica das espécies, baseada em literatura especializada de Lorenzi (2009), Lorenzi et al. (2010), auxílio de especialistas do Herbário de Porto Nacional, localizado no município de Porto Nacional - TO, registro fotográfico e no sistema Angiosperm Phylogeny Group III (APG III, 2009).

O levantamento foi realizado por meio do censo, considerando somente as espécies lenhosas com altura igual ou superior a dois metros ocorrentes nas ruas. Para todas as espécies foram apreciados os seguintes aspectos: nome científico; nome popular; família botânica; ocorrência natural (nativa ou exótica à flora original do Bioma Cerrado); desenvolvimento da raiz; necessidade de poda; diâmetro à altura do peito (DAP) (1,30 m do solo); altura total, feita pelo método da vara; altura da primeira bifurcação, realizada com fita métrica; estado fitossanitário conforme três categorias estabelecidas: boa, ruim e regular, adaptado de Boeni e Silveira (2011), (Tabela 1); além da frequência (\%), calculada através da razão entre número de indivíduos da espécie e o número total de indivíduos. Aquelas espécies localizadas em canteiros centrais e praças foram excluídas da pesquisa.

Para avaliar o desenvolvimento da raiz, foram consideradas as classes percentuais de Faria, Monteiro e Fisch (2007). Sendo estas: Sem interferência (100\%) - quando as raízes não estão expostas; Baixa interferência (70\%) - quando a árvore apresenta alguma raiz exposta na calçada, porém não chega causar nem um tipo de prejuízo; Média interferência (40\%) - quando a árvore apresenta várias raízes expostas na calçada, podendo causar algum tipo de prejuízo; 
Alta Interferência (20\%) - quando a árvore apresenta várias raízes expostas na calçada, já tendo causado algum tipo de prejuízo.

Tabela 1. Critérios utilizados para o estado fitossanitário (BOENI e SILVEIRA, 2011)

Table 1. Criteria used for phytosanitary status (BOENI e SILVEIRA, 2011)

\begin{tabular}{cl}
\hline Categoria & \multicolumn{1}{c}{ Critério } \\
\hline Boa & $\begin{array}{l}\text { Árvore vigorosa e sadia, sem sinais aparentes de ataque de insetos, doenças (tecidos } \\
\text { necrosados, secreções caulinares, galhos mortos) ou injúrias mecânicas; pequena ou } \\
\text { nenhuma necessidade de manutenção. }\end{array}$ \\
\hline Regular & $\begin{array}{l}\text { Médias condições de vigor e saúde, necessitando de pequenos reparos ou poda, } \\
\text { apresentando descaracterização da forma, sinais de ataque de insetos, doença e } \\
\text { sensível ataque por hemiparasitas (erva-de-passarinho). }\end{array}$ \\
\hline Ruim & $\begin{array}{l}\text { Avançado e irreversível declínio, apresentando ataque muito severo por insetos ou } \\
\text { injúria mecânica, descaracterizando sua arquitetura ou; sinais de doença que } \\
\text { aparentemente comprometem sua existência ou que se apresenta infestada por } \\
\text { hemiparasitas. Para ser recuperada necessita de tratamento fitossanitário rigoroso. }\end{array}$ \\
\hline
\end{tabular}

Foram levados em consideração, quanto à necessidade de poda, os seguintes aspectos: nenhuma - não há necessidade de poda no momento atual; leve - árvore necessita de uma poda leve para manutenção; pesada - necessidade de poda pesada em decorrência do contato com a fiação aérea, ou dificultando o tráfego de veículos e pedestres, podendo causar algum prejuízo; drástica - em virtude de danos ou outros problemas apresentados necessita de uma poda drástica.

A percepção ambiental dos moradores foi realizada através de um questionário constituído por questões objetivas e do tipo abertas, percorrendo-se todas as ruas do setor. Utilizou-se, para tanto, a metodologia de Triola (1999) para o cálculo de determinação do tamanho da amostra, com base em uma população finita heterogênea, com nível de confiança a 95\% e erro amostral máximo aceitável de 10\%, totalizando 79 residências, correspondendo a $18,20 \%$ do total de residências do setor. No entanto, a aplicação foi efetuada, por sorteio aleatório, em $30 \%$ das residências de cada rua, o que correspondeu a 130 residências. Quando os moradores das residências sorteadas não foram encontrados, ou quando foram sorteados lotes baldios, condomínios e comércios, foi escolhida a residência subsequente para aplicação do questionário. Foram excluídos desta pesquisa os condomínios, pelo motivo de os mesmos poderem possuir arborização própria e esse fato influir na percepção das pessoas.

A coleta de dados foi realizada no período de janeiro a julho de 2014.

\section{RESULTADOS E DISCUSSÃO}

A arborização das vias públicas do setor Jardim Sevilha da cidade de Gurupi - TO apresentou-se constituída de 212 indivíduos arbustivo-arbóreos e palmeiras, pertencentes a 19 famílias, 35 gêneros e 38 espécies. A espécie de maior ocorrência foi Licania tomentosa (Benth.) 
Fritsch. (oiti), com 54,25\% do total de indivíduos, seguida de Annona squamosa L. (ata), Paquira aquatica Aubl. (manguba), Psidium guajava L. (goiabeira) e Mangifera indica L. (manga) que juntas perfizeram 64,16 \% dos indivíduos inventariados. As demais espécies possuíam representatividade abaixo de $2 \%$, sendo que 16 delas apresentaram apenas um indivíduo (Tabela 2).

Tabela 2. Espécies ocorrentes na arborização urbana do setor Jardim Sevilha

Table 2. Species occurring in Jardim Sevilha District's urban afforestation

\begin{tabular}{|c|c|c|c|c|c|}
\hline Família & Nome científico & Nome popular & $\mathbf{O}^{*}$ & FA & FR \% \\
\hline \multirow{3}{*}{ Anacardiaceae } & Anacardiun ocidentalis L. & Caju & $\mathrm{N}$ & 3 & 1,42 \\
\hline & Mangifera indica L. & Manga & $\mathrm{E}$ & 5 & 2,36 \\
\hline & Schinus sp. & Almesca & $\mathrm{N}$ & 1 & 0,47 \\
\hline Annonaceae & Annona squamosa L. & Ata & $\mathrm{E}$ & 6 & 2,83 \\
\hline \multirow[t]{6}{*}{ Arecaceae } & $\begin{array}{l}\text { Roystonea oleracea (Jacq.) O.F. } \\
\text { Cook }\end{array}$ & Palmeira-imperial & $E$ & 4 & 1,89 \\
\hline & Cocos nucifera L. & Coco & $\mathrm{E}$ & 1 & 0,47 \\
\hline & Syagrus cocoides Mart. & Pupunha-brava & $\mathrm{N}$ & 2 & 0,94 \\
\hline & Syagrus oleracea (Mart.) Becc. & Gueroba & $\mathrm{N}$ & 2 & 0,94 \\
\hline & Bactris gasipaes Kunth & Pupunha & $\mathrm{E}$ & 3 & 1,42 \\
\hline & $\begin{array}{l}\text { Archontophoenix alexandrae } \mathrm{H} \text {. } \\
\text { Wendl. \& Drude }\end{array}$ & Palmeira-real & $E$ & 2 & 0,94 \\
\hline Asparagaceae & Beaucarnea recurvata Lem & Pé-de-elefante & $E$ & 1 & 0,47 \\
\hline \multirow[t]{3}{*}{ Bignoniaceae } & Tecoma stans (L.) Juss. ex Kunth & Ipê-mirim & $E$ & 1 & 0,47 \\
\hline & Crescentia cujete L. & Coité & $\mathrm{E}$ & 2 & 0,94 \\
\hline & Tabebuia serratifolia (Vahl.) Nich. & Ipê-amarelo & $\mathrm{N}$ & 3 & 1,42 \\
\hline Bixaceae & Bixa orellana L. & Urucum & $\mathrm{E}$ & 4 & 1,89 \\
\hline Bombacaceae & Paquira aquatica Aubl. & Manguba & $E$ & 5 & 2,36 \\
\hline Caricaceae & Carica papaya L. & Mamão & $E$ & 3 & 1,42 \\
\hline Chrysobalanaceae & Licania tomentosa (Benth.) Fritsch. & Oiti & $\mathrm{E}$ & 115 & 54,25 \\
\hline Combretaceae & Terminalia catappa L. & Sete-copas & $E$ & 3 & 1,42 \\
\hline Cycadaceae & Cycas circinalis L. & Cica & $E$ & 1 & 0,47 \\
\hline \multirow[t]{7}{*}{ Fabaceae } & Machaerium paraguariense Hassl. & Bico-de-pato & $\mathrm{N}$ & 1 & 0,47 \\
\hline & Caesalpinia echinata Lam & Pau-Brasil & $\mathrm{E}$ & 1 & 0,47 \\
\hline & Caesalpinia pulcherrima L. & Flamboyant-mirim & $\mathrm{E}$ & 1 & 0,47 \\
\hline & Tamarindus indica L. & Tamarindo & $\mathrm{E}$ & 1 & 0,47 \\
\hline & Delonix regia (Hook.) Raf & Flamboyant & $\mathrm{E}$ & 1 & 0,47 \\
\hline & Bauhinia variegata $\mathrm{L}$. & Pata-de-vaca & $\mathrm{E}$ & 1 & 0,47 \\
\hline & $\begin{array}{l}\text { Piptadenia gonoacantha (Mart.) } \\
\text { J.F.Macbr. }\end{array}$ & Pau-jacaré & $\mathrm{N}$ & 2 & 0,94 \\
\hline Lauraceae & Persea americana Mill. & Abacate & $E$ & 1 & 0,47 \\
\hline \multirow{2}{*}{ Malvaceae } & Gossypium sp. & Algodão & $\mathrm{E}$ & 1 & 0,47 \\
\hline & Guazuma ulmifolia Lam. & Mutamba & $\mathrm{N}$ & 1 & 0,47 \\
\hline \multirow[t]{2}{*}{ Moraceae } & Ficus benjamina L. & Figueira & $E$ & 2 & 0,94 \\
\hline & $\begin{array}{l}\text { Maclura tinctoria (L.) D.Don } \\
\text { exSteud. }\end{array}$ & Pau-bosta & $\mathrm{N}$ & 1 & 0,47 \\
\hline \multirow[t]{3}{*}{ Myrtaceae } & Syzygium jambos (L.) Alston & Jambo & $\mathrm{E}$ & 3 & 1,42 \\
\hline & Syzygium jambolanum D.C. & Azeitona & $\mathrm{E}$ & 1 & 0,47 \\
\hline & Psidium guajava $\mathrm{L}$. & Goiabeira & $\mathrm{E}$ & 5 & 2,36 \\
\hline Oleaceae & Jasminum sp & Jasmim & $E$ & 4 & 1,89 \\
\hline Oxalidaceae & Averrhoa carambola L. & Carambola & $E$ & 4 & 1,89 \\
\hline Salicaceae & Casearia sylvestris Sw & Folha-de-carne & $\mathrm{N}$ & 1 & 0,47 \\
\hline Desconhecida & Desconhecida & Desconhecida & 1 & 13 & 6,13 \\
\hline TOTAL & 38 & & & 212 & 100 \\
\hline
\end{tabular}

* $(\mathrm{O})$ Origem (N) Nativa (E) Exótica (FA) Frequência absoluta (FR) Frequência relativa. 
Os indivíduos não identificados serão instrumentos de pesquisas e estudos acadêmicos para posterior verificação da espécie ou classificação e catalogação da mesma.

No diagnóstico da arborização das vias públicas do município de Uchôa - SP, realizado por Stranghetti e Silva (2010), Licania tomentosa foi a espécie mais frequente com uma percentagem de 67,05\%, superior às cinco espécies mais frequentes encontradas neste trabalho. Em contrapartida, em um diagnóstico da arborização nas calçadas da região central de Gurupi - TO, realizado por Oliveira et al. (2017), a referida espécie foi a mais frequente, com $70,88 \%$ da população avaliada. Um dos motivos desta preferência é que a espécie é uma das principais produzidas no viveiro municipal, que é o principal fornecedor de mudas para arborização da cidade.

Recomenda-se como regra básica procurar densidades que não ultrapassem $30 \%$ de uma única família botânica e 10\% de uma única espécie (CEMIG, 2011). Licania tomentosa ultrapassou a devida recomendação, demonstrando uma distribuição irregular, sendo que as demais 37 espécies possuíam menos de 2,84\% de ocorrência cada. Destas, 62,16\% não chegavam a $1 \%$ de frequência relativa. Assim, embora a quantidade de espécies encontradas no presente trabalho seja considerada significativa, 37 espécies possuíam uma baixa percentagem relativa.

Dessa forma, poucas espécies representaram a maior parte da arborização do setor Jardim Sevilha, mesmo não sendo uma condição desejável. Alguns autores verificaram uma concentração maior de indivíduos distribuídos num pequeno número de espécies, entre eles: Melo, Lira Filho e Rodolfo Junior (2007), no bairro Bivar Olinto, Patos - PB; Stranghetti e Silva (2010), em vias públicas do município de Uchôa - SP; e Santos, José e Sousa (2013), em praças centrais de Gurupi - TO. Outros estudos verificaram uma concentração de indivíduos de Oiti na arborização urbana como em: Corumbataí do Sul - PR (MEIRA et al., 2015) com 4,14\%; Colíder e Matupá - MT (ALMEIDA; RONDON NETO, 2010) com 73,1\%.

Devido à predominância de Licania tomentosa, a família Chrysobalanaceae foi a mais representativa da população. As demais famílias com maior frequência de indivíduos foram Arecaceae (6.60\%), Anacardiaceae (4.25\%), Myrtaceae (4.25\%) e Fabaceae (3.77\%); as outras famílias possuíam frequência de indivíduos abaixo de $3 \%$. No entanto, considerando o número de espécies dentro da família, a mais representativa foi Fabaceae com 7 espécies.

É comum utilizar espécies exóticas na arborização urbana das cidades brasileiras. Em praças centrais de Gurupi - TO, Santos, José e Sousa (2013) encontraram 63,64\% de espécies exóticas ao Bioma Cerrado. No presente estudo, 26,32\% das espécies eram nativas do respectivo bioma, enquanto que $73,68 \%$ eram exóticas. Todavia, em relação ao total de indivíduos, 91,98\% eram exóticos e somente 8,02\% eram nativos do bioma. Este resultado mostrou que a maioria dos indivíduos implantados no Jardim Sevilha não corresponde à 
realidade do Cerrado. Resultados semelhantes foram encontrados por Sampaio et al. (2011), na arborização de vias públicas dos bairros analisados na cidade de Campo Mourão - PR, em que $73,07 \%$ das espécies registradas enquadraram-se como exóticas distribuídas como procedentes de outras regiões fitogeográficas. Outros estudos encontraram valores semelhantes ou menores, em outros locais do país, tais como: 75,9\% em Maringá - PR (BLUM; BORGO; SAMPAIO, 2008); 66,7\% em duas cidades da região norte do estado de MT (ALMEIDA; RONDON NETO, 2010); 18\% em Farol - PR (HOPPEN et al., 2014); 17,03\% em Corumbataí do Sul - PR (MEIRA et al., 2015). Contudo, é recomendado o uso de espécies nativas, por estarem mais bem adaptadas às condições locais, mantendo o equilíbrio ecológico e servindo de atrativo para a fauna. Desta forma, sugere-se plantar mais indivíduos de espécies nativas da região.

Os espécimes inadequados do Jardim Sevilha, sendo dois exemplares de Ficus benjamina L., foram retirados após a coleta de dados, devido ao confronto com a fiação elétrica e de telefonia, desestruturação da calçada e do avanço da copa à rua que prejudicava o tráfego de veículos. Tais observações não foram detalhadas neste estudo.

Dentre as ruas do setor Jardim Sevilha, verificou-se que a Rua Alcacar foi a mais arborizada (28) e com o maior número de espécies. Nesta rua foi podado drasticamente o espécime de Machaerium paraguariensis Hassl. (bico-de-pato), após a coleta de dados, por causa do grande porte evidenciado. A Rua Badejós apresentou o menor número de indivíduos (4), evidenciando, desse modo, uma diferença acentuada, em decorrência da falta de um planejamento adequado (Tabela 3). Na Alameda Madri foi contado apenas os indivíduos existentes nas calçadas, excluindo o canteiro central da avaliação por ser bastante arborizado e esse fato interferir na comparação com as ruas.

Tabela 3. Percentual de ocorrência de $L$. tomentosa nas ruas do setor Jardim Sevilha Table 3. Percentage of occurrence of $L$. tomentosa on the streets of Jardim Sevilha's District

\begin{tabular}{lcccc}
\hline Rua & $\begin{array}{c}\text { Total de } \\
\text { Indivíduos }\end{array}$ & $\begin{array}{c}\text { Número de } \\
\text { espécies }\end{array}$ & $\begin{array}{c}\text { Número de } \\
\text { Oiti }\end{array}$ & (\%) Oiti \\
\hline Cartogena & 19 & 4 & 16 & 84,2 \\
\hline Toledo & 25 & 5 & 20 & 80,0 \\
\hline Alameda Madri & 8 & 2 & 6 & 75,0 \\
\hline Saragoça & 8 & 3 & 6 & 75,0 \\
\hline Alcacar & 28 & 11 & 17 & 60,71 \\
\hline Barcelona & 25 & 6 & 15 & 60,0 \\
\hline Badejós & 4 & 3 & 2 & 50,0 \\
\hline Burgos & 21 & 6 & 10 & 47,6 \\
\hline Balcares & 23 & 8 & 10 & 43,48 \\
\hline Murcia & 8 & 6 & 3 & 37,5 \\
\hline Edre & 12 & 5 & 3 & 25,0 \\
\hline Sardenha & 12 & 8 & 3 & 25,0 \\
\hline Alicante & 19 & 9 & 4 & 21,10 \\
\hline TOTAL & 212 & & 115 & \\
\hline
\end{tabular}


As ruas Alcacar, Alicante, Balcares e Sardenha apresentaram maior diversidade de espécies. A Rua Alicante mostrou-se mais equilibrada no quesito número de indivíduos por espécie, haja vista que apresentou percentualmente o menor número $(21,10 \%)$ de indivíduos de Oiti. De outra forma, as ruas Cartogena e Toledo apresentaram 84,2 e 80\% desses indivíduos, respectivamente.

Observou-se que a maioria dos indivíduos (arbustivo-arbóreos e palmeiras) do setor encontrava-se em boas condições fitossanitárias (53,77\%). A arborização das vias públicas avaliadas apresentou $41,04 \%$ dos indivíduos em condições regulares de saúde e vigor, necessitando de pequenos reparos e 5,19\% em estado avançado e irreversível declínio (Figura 2). O resultado deste trabalho foi superior ao verificado em Jacareí - SP (FARIA; MONTEIRO; FISCH, 2007), onde $40 \%$ dos indivíduos amostrados não apresentaram sinais aparentes de algum tipo de injúrias.

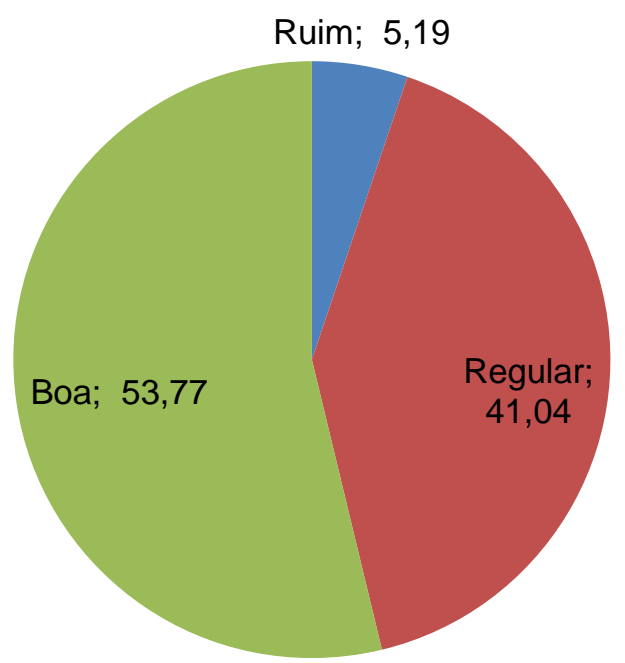

Figura 2. Condições fitossanitárias dos indivíduos arbustivo-arbóreos e palmeiras do Jardim Sevilha Figure 2. Phytosanitary conditions of shrub-tree individuals and palm trees of Jardim Sevilha

Estudos realizados em outras cidades brasileiras, como em Porto Alegre - RS, feito por Boeni e Silveira (2011), encontraram 72,9\% dos indivíduos em boas condições de saúde; Melo, Lira Filho e Rodolfo Junior (2007) observaram 88,47\% das árvores em bom estado, resultado semelhante ao verificado por Coletto, Müller e Wolski (2008), no município de Sete de Setembro - RS, onde a grande maioria (86,4\%) foi classificada como árvore boa, vigorosa, que não requer trabalhos de correção; Stranghetti e Silva (2010) constataram que 96,5\% dos indivíduos amostrados não apresentaram sinais aparentes de algum tipo de injúria.

A maioria dos indivíduos não necessitava de poda $(51,89 \%)$, devido à grande parte dos indivíduos já estar podada, em consequência do local que se encontra (sob a fiação aérea), isto sendo feito em boa parte pelos próprios moradores; enquanto que 30,66\% precisariam ser podados levemente e $15,09 \%$ de forma pesada. Outros 2,36\% necessitavam de poda drástica. 
Recomenda-se a substituição ou retirada destes exemplares, em consequência de danos e outros pelo estado avançado e irreversível declínio (fitossanidade), por espécies de menor porte, resistentes e que possuem raiz pivotante (Figura 3).

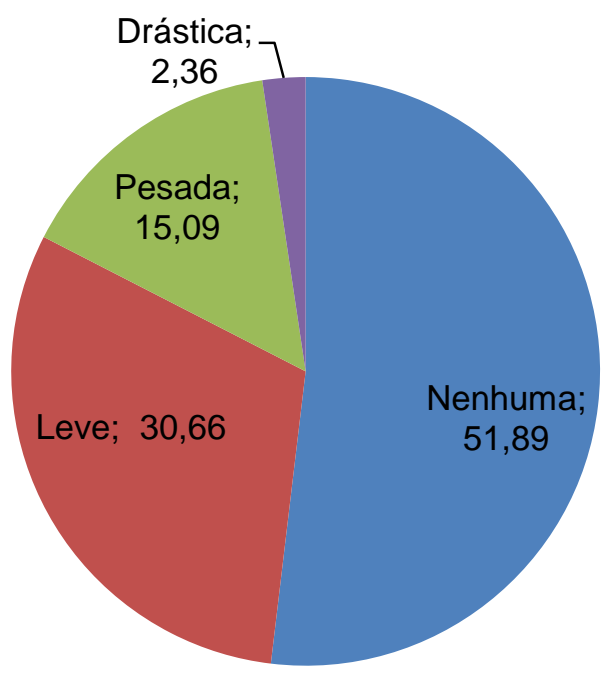

Figura 3. Necessidade de poda dos indivíduos arbustivo-arbóreos e palmeiras do Jardim Sevilha Figure 3. Need for pruning of shrub-trees and palm trees of Jardim Sevilha

$\mathrm{Na}$ análise da necessidade de poda, realizada por Melo, Lira Filho e Rodolfo Junior (2007) no Bairro Bivar Olinto, Patos - PB, 67,68\% dos indivíduos não necessitavam de poda. Segundo os autores, isto se deu devido aos cuidados tomados pelos moradores do bairro, pois durante o estudo foram observados que esses moradores se preocupavam com as árvores que se encontravam em frente às suas casas, tendo certo zelo, podando-as, aguando-as e adubando-as. Esses cuidados foram observados no setor Jardim Sevilha, em menor proporção.

Conforme Stranghetti e Silva (2010), a utilização de podas pode ser evitada, desde que, durante o planejamento da arborização seja feita a escolha correta da espécie a ser plantada e a sua localização.

Com relação ao desenvolvimento da raiz, foi observado que em 47,64\% dos indivíduos, as raízes não estavam expostas. Em contrapartida, em 52,36\% havia algum tipo de interferência, sendo $39,15 \%$ de baixa interferência, e somente 0,94\% apresentando alta interferência (Figura 4). 


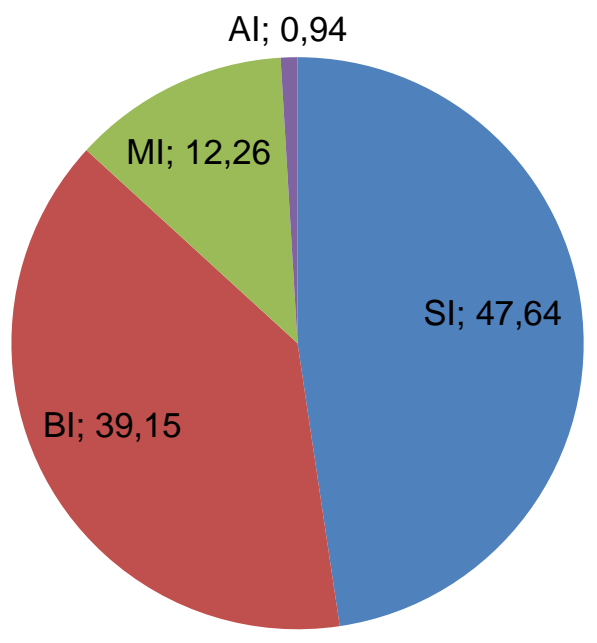

Figura 4. Condição do desenvolvimento da raiz: Sem interferência (SI), Baixa interferência (BI), Média Interferência (MI), Alta Interferência (Al)

Figure 4. Root development condition: No interference (SI), Low interference (BI), Medium Interference (MI), High Interference (AI)

Stranghetti e Silva (2010) no município de Uchôa - SP observaram que 36,21\% dos indivíduos amostrados apresentavam interferência das raízes nas calçadas devido à utilização de espécies de sistema radicular superficial, como Ficus benjamina, Pachira aquatica, Terminalia catappa e Caesalpinia peltophoroides Benth. (sibipiruna), que quando plantadas em área reduzida geram trincas e comprometem a pavimentação, em decorrência da pressão exercida pelas raízes secundárias que são mais desenvolvidas que a raiz pivotante e se dispõem em feixes paralelos ao solo. Ficus benjamina, Pachira aquatica, Terminalia catappa e a maioria dos indivíduos de Licania tomentosa apresentaram problemas nas calçadas do Jardim Sevilha.

Paiva (2009) ressaltou que muitas vezes, os danos às calçadas não são provocados pelas raízes, mas pela ação mecânica do crescimento secundário (em diâmetro) do tronco das árvores, extrapolando a área livre sem pavimento. Embora não tenham sidos avaliados neste trabalho, observaram-se dimensões de áreas livres (sem pavimento) insuficientes nas calçadas do Jardim Sevilha, responsáveis, em parte, pelos danos observados.

Com base na altura total, foi observado que 54\% dos indivíduos apresentaram porte baixo, de 2 a 5 metros. Para 45,06\%, observou-se o intervalo de 5,1 a 10 metros, e em apenas 0,94\% constatou-se altura maior que 10 metros. O porte baixo da maioria das plantas avaliada pode estar relacionado à realização periódica de podas, ou por fins meramente estéticos ou para mantê-las com um porte inferior à altura da rede elétrica e de telefonia. Tais podas foram notadas durante o levantamento da arborização.

Ao se avaliar o diâmetro a altura do peito (DAP), percebeu-se $43,19 \%$ dos indivíduos com diâmetro maior ou igual a 15 centímetros. Outros 20,66\% possuíam de 10 a menos de 15 
centímetros, perfazendo $63,85 \%$ dos indivíduos avaliados. Assim, os demais $36,15 \%$ das plantas possuíam menos de 10 centímetros de DAP.

Em relação à altura da primeira bifurcação, menos de 4\% das plantas apresentavam a altura considerada ideal para facilitar a passagem de pedestres (2m). Essa situação pode ser explicada pelo motivo de os exemplares terem sido plantados e conduzidos erroneamente, sem uma orientação técnica, e parte por estarem ainda jovens. Este resultado mostra que deve ser realizada uma condução das plantas utilizadas na arborização urbana, para que estas não venham a possuir problemas semelhantes no futuro (MELO; LIRA FILHO; RODOLFO JUNIOR, 2007).

\section{Percepção ambiental}

Foram visitadas 130 residências, das quais 100\% dos moradores participaram da entrevista, sendo questionado um morador por casa. Os entrevistados possuíam entre três meses a trinta e cinco anos de residência no local, observando-se $44,6 \%$ com mais de 15 anos.

Das residências analisadas, 43,84\% possuíam árvore ou arbusto em frente a casa, sendo que $90 \%$ destes indivíduos foram os próprios moradores que plantaram. Com estes dados observou-se interesse desses moradores com as plantas, haja vista aos cuidados observados. Entre eles destacaram-se a poda e a irrigação.

Quando questionados se gostam da arborização do setor, 90\% dos moradores sinalizaram que sim, segundo a maioria desses, porque 'faz sombra', 'diminui a temperatura', 'protege', 'fornece oxigênio' e 'é importante para o meio ambiente'. Por outro lado, 4,62\% disseram que não. Parte destes porque cai muita folha. Outros 5,38\% não responderam ou não souberam opinar.

Em relação à arborização do Jardim Sevilha, 42,3\% dos moradores a classificaram como boa; regular 32,3\% e 18,46\% como ruim (Figura 5).

Dos entrevistados que avaliaram como Ótima mais de $85 \%$ residia na Alameda Madri, a qual possui o canteiro central arborizado excluído da pesquisa. Entre os que consideraram a arborização Boa, mais de 90\% morava nas ruas Alcacar, Barcelona, Burgos, Balcares e Toledo, sendo estas as mais arborizadas do setor. A maioria dos que classificaram a arborização na categoria Ruim morava nas ruas menos arborizadas, demonstrando, assim, respostas mais subjetivas e de acordo com a realidade local (rua, calçada). 


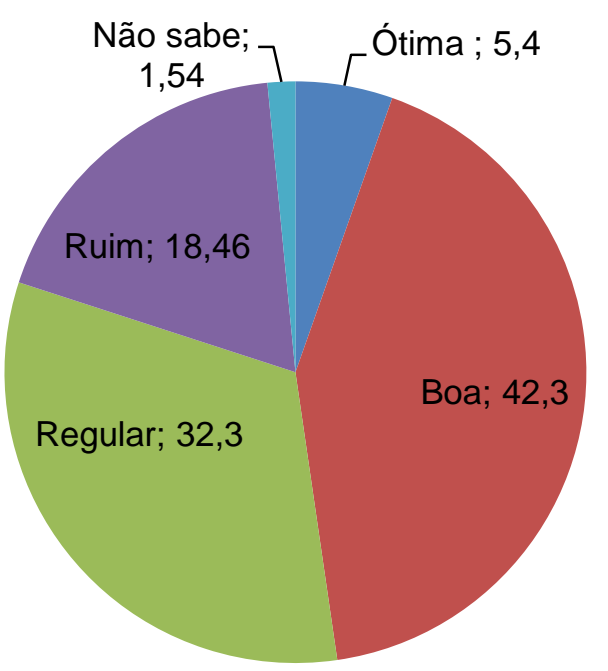

Figura 5. Classificação da arborização das vias públicas do Jardim Sevilha Figure 5. Public roads afforestation rating of Jardim Sevilha

Constatou-se $62,3 \%$ dos moradores afirmando não ser suficiente o número de árvores existentes nas ruas do setor, dos quais, uma parcela argumentou a necessidade de se plantar mais árvores. Observou-se também $68,5 \%$ dos residentes aduzindo ter conhecimento sobre a importância da arborização em vias públicas. Outros 27,7\% disseram não ter conhecimento, e apenas 3,8\% não souberam ou não responderam. A maioria dos moradores mostrou interesse pelas árvores, arbustos e demais áreas verdes do setor Jardim Sevilha.

Roppa et al. (2007), em um diagnóstico da percepção dos moradores, observaram bom nível de esclarecimento no que se refere à arborização urbana, uma vez que a maioria mostrou conhecimento a respeito de questões que abordavam a importância da arborização, seus benefícios e qualidade de vida.

Entre os benefícios que justificam a importância da arborização apontada pelos moradores, estão à diminuição da temperatura e o fornecimento de sombra. Além disso, 8,02\% do total dos entrevistados apontaram o conjunto (Ameniza a temperatura, Fornece sombra, É confortável) como um grande benefício da arborização da malha urbana (Tabela 4).

Vale salientar que nesta questão, os moradores puderam opinar em mais de um item, explicando, desse jeito, os resultados.

Tabela 4. Benefícios que justificam a importância da arborização apontada pelos moradores Table 4. Benefits that justify the importance of afforestation by residents

\begin{tabular}{lc}
\hline Características da importância & Percentual observado (\%) \\
\hline Fornece sombra & 53,84 \\
\hline É confortável & 10,37 \\
\hline Ameniza a temperatura & 26,88 \\
\hline O conjunto & 8,02 \\
\hline Outro & 9,90 \\
\hline
\end{tabular}


O fornecimento de sombra foi a característica mais mencionada pelos entrevistados $(53,84 \%)$, seguida da amenização da temperatura (26,88\%). Estes benefícios também foram observados por Roppa et al. (2007) e Brun, Longhi e Brun (2009), ambos em Santa Maria - RS, em que 83,1 , e $81,1 \%$ para produção de sombra e 49,2 e $52,7 \%$ para redução do calor, respectivamente. Outros autores registraram resultados importantes quanto às vantagens e/ou benefícios ambientais oferecidos pela arborização urbana, entre eles: Viezzer et al. (2016), em Curitiba - PR.

A opção "Outro" é subjetiva e refere-se na maior parte, conforme os devidos moradores, à interceptação de água da chuva, abrigo para avifauna, purificação do ar, absorção de gases poluentes, controle hidrológico e fornecimento de oxigênio. Nota-se, pelas respostas, que tais moradores possuem conhecimento a respeito dos benefícios da arborização.

\section{CONCLUSÕES}

Concluiu-se que houve uma boa diversidade de espécies na arborização do setor, entretanto, Licania tomentosa apresentou $54,25 \%$ do total dos indivíduos inventariados, sendo que as demais 37 espécies possuíam baixa frequência, menos de 3\% cada. Ademais, 73,68\% das espécies eram exóticas ao Bioma Cerrado, enquanto que 26,32\% eram nativas. Além disso, a maioria dos indivíduos $(91,98 \%)$ era exótica e somente $8,02 \%$ nativos do respectivo bioma. Portanto, faz-se necessário o estudo e a divulgação de espécies nativas com potencial para a arborização.

A maioria dos espécimes encontrava-se em boas condições fitossanitárias, no entanto, com relação ao desenvolvimento da raiz foi observado que em 52,36\% havia algum tipo de interferência, necessitando dos devidos reparos e correções.

Os moradores do Jardim Sevilha, em sua maioria, demonstraram conhecimento sobre a importância da arborização em vias públicas e afirmaram não ser suficiente o número de árvores existentes nas ruas do setor (62,3\%). Contudo, 90\% dos entrevistados sinalizaram que gostam da arborização, sendo que, entre os benefícios mais destacados estão o fornecimento de sombra e a amenização da temperatura, que se relacionam. 


\section{REFERÊNCIAS}

ALMEIDA, D. N.; RONDON NETO, R. M. Análise da arborização urbana de duas cidades da região norte do estado de Mato Grosso. Revista Árvore, Viçosa, v. 34, n. 5, p. 899-906, 2010.

ANGIOSPERM PHYLOGENY GROUP (APG). An update of the Angiosperm Phylogeny Group classification for the orders and families of flowering plants: APG III. Botanical Journal of the Linnean Society, [S.I], v. 161, n. 2, p. 105-121, 2009.

BLUM, C. T.; BORGO, M.; SAMPAIO, A. C. F. Espécies exóticas invasoras na arborização de vias públicas de Maringá-PR. Revista da Sociedade Brasileira de Arborização Urbana, Piracicaba, v. 3, n. 2, p. 78-97, 2008.

BOBROWSKI, R.; BIONDI, D.; FIGUEIREDO FILHO, A. Dinâmica da distribuição diamétrica na arborização de ruas da cidade de Curitiba, Paraná, Brasil. Scientia Forestalis, Piracicaba, v.40, n.94, p.167-178, 2012.

BOENI, B. de O.; SILVEIRA, D. Diagnóstico da arborização urbana em bairros do município de Porto Alegre, RS, Brasil. Revista da Sociedade Brasileira de Arborização Urbana, Piracicaba, v.6, n.3, p.189-206, 2011.

BRUN, F.G.K.; LONGHI, S.J.; BRUN, E.J. Estudo da percepção da população de vilas do Bairro Camobi, Santa Maria - RS sobre a arborização urbana. REA - Revista de Estudos Ambientais, Blumenau, v.11, n. 1, p. 6-21, 2009.

COLETTO, E.P.; MÜLLER, N.G.; WOLSKI, S.S. Diagnóstico da arborização das vias públicas do município de Sete de Setembro - RS. Revista da Sociedade Brasileira de Arborização Urbana, Piracicaba, v.3, n.2, p.110-122, 2008.

COMPANHIA ENERGÉTICA DE MINAS GERAIS/ CEMIG. Manual de arborização. Belo Horizonte: CEMIG, 2011. 112 p.

FARIA, J.L.G.; MONTEIRO, E.A.; FISCH, S.T.V. Arborização de vias públicas do município de Jacareí - SP. Revista da Sociedade Brasileira de Arborização Urbana, Piracicaba, v.2, n.4, p.20-33, 2007.

GOMES, P. B. (Org). Manual para elaboração do plano municipal de arborização urbana. Paraná: $2012 . \quad$ Disponível em: <http://www.meioambiente.mppr.mp.br/arquivos/File/planejamento_estrategico/6_Manual_PMA RB.pdf>. Acesso em: 10 mai. 2016.

HOPPEN, M. I.; DIVENSI, H. F.; RIBEIRO, R. F.; CAXAMBÚ, M. G. Espécies exóticas na arborização de vias públicas no município de Farol, PR, Brasil. Revista da Sociedade Brasileira de Arborização Urbana, Piracicaba, v. 9, n. 3, p. 173-186, 2014.

LORENZI, H. Árvores brasileiras: manual de identificação e cultivo de plantas arbóreas nativas do Brasil. 1.ed. Nova Odessa: Instituto Plantarum, 2009. 384p.

LORENZI, H.; KAHN, F.; NOBLICK, L.R.; FERREIRA, E.F. Flora Brasileira Lorenzi. Nova Odessa: Instituto Plantarum, 2010. 368p. 
MEIRA, G. R. N.; TEXEIRA, G. G. M.; VENTURIN, P. R. F.; GOTTSTEIN, P.; CAXAMBU, M. G. Avaliação quali-quantitativa de espécies arbóreas no perímetro urbano da cidade de Corumbataí do Sul - PR. Revista da Sociedade Brasileira de Arborização Urbana, Piracicaba, v. 10, n. 4 , p. 36-49, 2015.

MELO, R. R. de.; LIRA FILHO, J. A.; RODOLFO JÚNIOR, F. R. Diagnóstico qualitativo e quantitativo da arborização urbana no bairro Bivar Olinto, Patos, Paraíba. Revista da Sociedade Brasileira de Arborização Urbana, Piracicaba, v. 2, n. 1, 2007.

OLIVEIRA, L. M.; SANTOS, A. F.; SOUZA, P. A.; ALVES, K. C. C. L. F.; GIONGO, M. Diagnóstico da arborização nas calçadas de Gurupi - TO. Revista da Sociedade Brasileira de Arborização Urbana, Piracicaba, v.12, n.1, p. 105-121, 2017.

PAIVA, A.V. Aspectos da arborização urbana do centro de Cosmópolis - SP. Revista da Sociedade Brasileira de Arborização Urbana, Piracicaba, v.4, n.4, p.17-31, 2009.

ROPPA, C.; FALKENBERG, J.R.; STANGERLIN, D.M.; GIZELE, F.; BRUN, K.; BRUN, E.J.; LONGHI, S.J. Diagnóstico da percepção dos moradores sobre a arborização urbana na Vila Estação Colônia - Bairro Camobi, Santa Maria - RS. Revista da Sociedade Brasileira de Arborização Urbana, Piracicaba, v.2, n.2, p.11-30. 2007.

SAMPAIO, A.C.F.; ECKER, A.E.A.; MARANGONI, C.J.M.; FIORESE, L.M.R.; SORDI, E.A. Espécies exóticas invasoras na arborização de vias públicas de três bairros de Campo Mourão - PR. Campo Digit@I, v.6, n.1, p.31-43, 2011.

SANTOS, A. F.; JOSÉ, A. C.; SOUZA, P. A. Fitossociologia e diversidade de espécies arbóreas das praças centrais do município de Gurupi - TO. Revista da Sociedade Brasileira de Arborização Urbana, Piracicaba, v. 8, n. 4, p. 36-46, 2013.

SECRETARIA DO PLANEJAMENTO E DA MODERNIZAÇÃO DA GESTÃO PÚBLICA (SEPLAN) 2013. GURUPI - SEPLAN - Governo do Estado do Tocantins. Disponível em: <http://www.seplan.to.gov.br/Arquivos/download/Municipios_Perfil_2013/Gurupi.pdf> Acesso em: 15 jul. 2017.

SECRETARIA MUNICIPAL DE INFRAESTRUTURA (SMI) - Prefeitura Municipal de Gurupi. Plano Municipal de Água e Esgoto PMAE. Gurupi. 2013. 105p. Disponível em: <http://w ww.gurupi.to.gov.br/resources/arquivos-publicados/planos-municipais/agua_esgoto_2013.pdf>. Acesso em: 1 set. 2016.

STRANGHETTI, V.; SILVA, Z. A. V. Diagnóstico da arborização das vias públicas do município de Uchôa - SP. Revista da Sociedade Brasileira de Arborização Urbana, Piracicaba, v.5, n.2, p.124-138, 2010.

TRIOLA, M. F. Introdução à Estatística. 7. ed. Rio de Janeiro: LTC, 1999.

VIEZZER, J.; BIONDI, D.; BATISTA, A. C.; BRANDT, D. Perfil dos usuários e sua percepção dos elementos de composição paisagística das praças de Curitiba - PR. Revista da Sociedade Brasileira de Arborização Urbana, Piracicaba, v. 11, n. 3, p. 1-16, 2016. 